\title{
Radiographic imaging of an intra-aortic balloon pump impersonating a misplacement in the superior vena cava due to a right-sided aortic arch
}

\author{
Hanzhou Li, ${ }^{1}$ Gyanendra K Sharma, ${ }^{2}$ Jayanth H Keshavamurthy ${ }^{1}$
}

\begin{abstract}
${ }^{1}$ Department of Radiology, Augusta University Medical College of Georgia, Augusta, Georgia, USA

2Department of Medicine, Division of Cardiology, Augusta University Medical College of Georgia, Augusta, GA, USA
\end{abstract}

Correspondence to Mr Hanzhou Li,

hanli@augusta.edu

Accepted 18 May 2017
CrossMark

To cite: Li H, Sharma GK, Keshavamurthy JH. BMJ Case Rep Published Online First: [please include Day Month Year]. doi:10.1136/bcr-2017 220569

\section{DESCRIPTION}

A 48-year-old man with a history of coronary heart disease underwent a left heart catheterisation for non-ST-segment myocardial infarction. Coronary angiography revealed significant stenosis of the left anterior descending artery and right coronary artery (LAD/RCA). Transthoracic echocardiogram showed severely dilated left ventricle (LV), moderate concentric LV hypertrophy, an LV ejection fraction of $26 \%$ and elevated right ventricular systolic pressure of $40-45 \mathrm{~mm} \mathrm{Hg}$. An intra-aortic balloon pump (IABP) was placed for haemodynamic support through a right femoral artery insertion site. The patient later received a saphenous vein graft (SVG) to the RCA, an SVG to the left obtuse marginal artery and a left internal mammary artery graft to the LAD. On the postoperative chest X-ray, the IABP was visualised overlying the right hilar region, thatevoked alarming concern of possible misinsertion into the superior vena cava (SVC) through an arteriovenous fistula or through the femoral vein (figure 1). Delayed access to the angiogram images on the Picture Archiving and Communication System and a normal aortic arch reported on the patient's echocardiogram complicated the situation. The crisis resolved only after the attending cardiologist revealed his acknowledgement of the right-sided aortic arch. Over the course

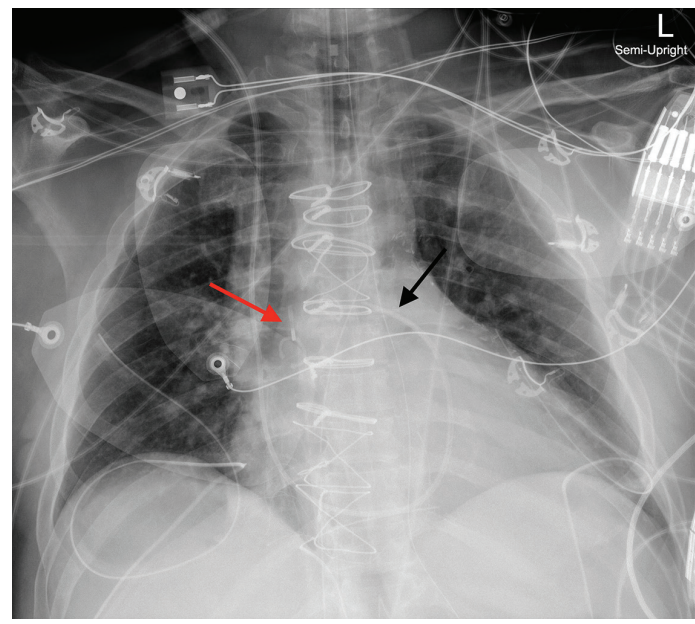

Figure 1 Postcoronary artery bypass graft chest X-ray showing sternotomy wires. The intra-aortic balloon pump overlies the right hilar region (red arrow). A Swan-Ganz catheter for measuring cardiac pressures can be seen curving in a ' $U$ ' shape from the right internal jugular vein through the heart and to the pulmonary artery (black arrow). of the next day, the patient was weaned off vasoactive medications and had the IABP withdrawn but later developed ventricular fibrillation. Subsequent cardiac catheterisation showed acute SVG failure to the RCA and left marginal artery. A stent was placed in the RCA and the patient was restarted on an IABP. Over the week, the patient's status improved and the IABP was removed. He was discharged with arrangements for a LifeVest defibrillator and a follow-up appointment.

A right-sided aortic arch is an infrequent congenital anomaly that often remains asymptomatic in adults. ${ }^{1}$ Typically, radiographic evidence includes the absence of an aortic knob visualised on a chest X-ray, leftward deviation of the trachea or an aortic protrusion on the right side of the trachea. However, such features on a chest X-ray are not always present as evident from our case. To receive a definitive visualisation of a right-sided aortic arch, a CT angiography (CTA) provides a great demonstration of the deviated structure; however, a CTA may not always be ordered in time when emergent cardiovascular interventions are required. ${ }^{2}$ Alternatively, an available coronary angiogram may demonstrate a right-sided aortic arch if the proximal part of the catheter is in the descending aorta and lies to the right of the vertebral column (figure 2).

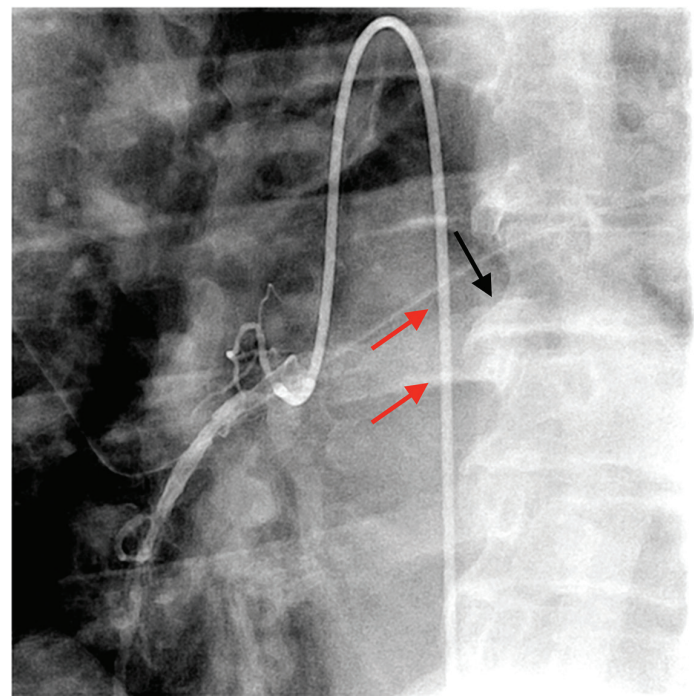

Figure 2 Coronary angiogram showing the course of the cardiac catheter through the descending aorta to the right coronary artery (red arrows). The course of the catheter is to the right of the vertebral column (black arrow). 
To our knowledge, this is the only documented chest X-ray of an IABP in a right-sided aortic arch. Besides a right-sided aortic arch, possible explanations include misplacement of the IABP in the SVC through a femoral vein insertion site or through an arteriovenous fistula. Presumably, the cardiologists noticed the right-sided aortic arch during the IABP placement but it was not communicated on the chest radiograph requisition. Thus this

\section{Learning points}

- Intra-aortic balloon pump overlying the right hilar region on a chest X-ray may indicate the presence of a right-sided aortic arch.

- Coronary angiogram can demonstrate the presence of a right-sided aortic arch by examining the path of the catheter to the heart.

- Documentation of atypical findings early in the care of a patient may reduce confusion in subsequent care management. case highlights the importance of detailing atypical findings on radiograph requisitions as soon as its presence is recognised to prevent diagnostic confusion.

Contributors JHK was involved in the care of the patient and thus contributed to the planning of the manuscript and framing of the teaching points. JHK was also involved in drafting and editing portions of the manuscript involving radiologic interpretation. $\mathrm{HL}$ was involved in consenting the patient and the drafting of the case presentation and conclusions. HL and JHK are the guarantors. GKS was also involved in the care of the patient and thus contributed to the cardiology insights regarding the case. GKS also contributed by thoroughly revising the manuscript.

Competing interests None declared.

Patient consent Obtained.

Provenance and peer review Not commissioned; externally peer reviewed.

(c) BMJ Publishing Group Ltd (unless otherwise stated in the text of the article) 2017. All rights reserved. No commercial use is permitted unless otherwise expressly granted.

\section{REFERENCES}

1 Cinà CS, Althani H, Pasenau J, et al. Kommerell's diverticulum and right-sided aortic arch: a cohort study and review of the literature. J Vasc Surg 2004;39:131-9.

2 Lale P, Toprak U, Kaya T; Uyanık. Variations in the Branching Pattern of the Aortic Arch detected with Computerized tomography angiography. Adv Radiol 2014;2014:1-6

Copyright 2017 BMJ Publishing Group. All rights reserved. For permission to reuse any of this content visit http://group.bmj.com/group/rights-licensing/permissions.

BMJ Case Report Fellows may re-use this article for personal use and teaching without any further permission.

Become a Fellow of BMJ Case Reports today and you can:

- Submit as many cases as you like

- Enjoy fast sympathetic peer review and rapid publication of accepted articles

- Access all the published articles

- Re-use any of the published material for personal use and teaching without further permission

For information on Institutional Fellowships contact consortiasales@bmjgroup.com

Visit casereports.bmj.com for more articles like this and to become a Fellow 